\title{
Correlation Research on College Oral English Teaching and Interpretation
}

\author{
Liu Xiaoyi \\ Foreign Language Department \\ Jilin Business and Technology College \\ Changchun, China \\ 182076127@qq.com
}

\begin{abstract}
With the quickening pace of internationalization, the role and status of interpretation in diplomatic activities are becoming obviously important. The interpretation courses are also emerging in college English education endlessly with their benefits. Interpretation, however, taking training skills as the main purpose, hasn't been taken for granted as a major course seriously. Most of interpreting textbooks still take piling up all kinds of interpreting vocabulary and reading materials as the main content and ignore the fact that interpretation is an integrated discipline with the collection of listening, speaking, reading, writing and translating skills. Interpreting teaching in university, therefore, should firstly consider the relationship between interpretation and the five English skills. Oral English, as one of the essential skills of interpreting teaching, is obviously correlated with interpreting research. In terms of the importance of the relationship between interpretation and oral English, this paper has carried out the correlation research in combination of theory and practice in order to explore the deep relationship between oral English and interpreting, guiding the further development of college oral English teaching.
\end{abstract}

Keywords-College English teaching; Oral English; Interpretation; Correlation

\section{THE IMPORTANCE OF CORRELATION RESEARCH ON INTERPRETATION AND ORAL ENGLISH}

Language interpretation is the practice of facilitating oral and sign-language communication, either simultaneously or consecutively, between two or more users of different languages. Functionally, interpreting and interpretation are both descriptive words for this process. In professional practice, interpreting denotes the act off facilitating communication from one language form into its equivalent, or approximate equivalent, in another language form. Interpretation denotes the actual product of this work, that is, the message as thus rendered into speech, sign language, writing, non-manual signals, or other language form. This important distinction is observed to avoid confusion. Functionally, an interpreter is a person who converts a thought or expression of a source language into an expression with a comparable meaning in a target language in "real time". The interpreter's function is to convey every semantic element (tone and register) and every intention and feeling of the message that the source-language speaker is directing to the target-language recipients.

As to the relationship between oral English and interpretation, most scholars have conducted researches and proposed their viewpoints on the difference between oral English and interpretation, but there is almost no research conducted on the correlation between oral English and interpretation in the past years. In the college English teaching, most students' form their interpretation ability from oral English speaking[1].

In college English teaching, interpreting as a compulsory course, is closely linked with oral English and its importance is self-evident, which is indispensable for the cultivation of students' three basic skills: listening, speaking and translation. In the process of interpretation, simultaneous interpretation in particular, there is no doubt that listening, speaking and translation exist and occur almost at the same time. Interpretation can be generally divided into two stages, namely input of listening and output of translating and speaking.

That is to say, speaking and translating exist in the meanwhile to perform their own functions, collectively known as the output stage of interpretation, which constitutes the focus of college English teaching, oral English teaching. However, what is the relevance of speaking and interpreting? How to associate training students' oral English ability with improving their interpreting level for a certain effect? The author, in the years of English teaching theory research and practice, finds that little attention has been paid to the correlation of oral English teaching and interpreting in the current English education. Teachers who have a fuzzy understanding of the relationship between oral English and interpretation are unable to form a scientific and systematic teaching method to essentially highlight oral English teaching efficiency. In today's society, there is an urgent demand for interpreting talents and the development of modernization also requires a higher ability of interpretation, which determines oral English teaching targets need to be adjusted to adapt the market. As a breakthrough point, this paper tries to make further analysis and argumentation of the correlation between oral English and interpretation[2].

\section{INTERPRETATION}

\section{A. Definition to interpretation}

Interpreting is a verbal and mental process to extract the information in source language in the limited time and convert it into another language. In interpreting process, the translator aims to convey the information meaning of source language 
accurately by representing the language information. This is the difference between interpretation and translation. Since interpreter must absorb the speaker's language information, the speaker's voice, tone and pronunciation has an inevitable influence on interpreting.

The term "translate”, "translator" or "translation” is used when tie immediate result of the work is a written text; and the term "interpret", "interpreter" or "interpretation", when the immediate result is a speech reproduced orally in a language (always in one of the working languages) other than that spoken by the original speaker.

Most importantly, an interpreter must also enjoy the idea of serving as a human bridge between two persons from different linguistic and cultural worlds. The act of interpretation makes government, courts, medical services, social services, law enforcement, education, and business accessible to limited and non-English speaking persons. For this reason, interpretation is a noble profession that requires dedication to excellence and commitment. It is hard work, but very beneficial work.

\section{B. Features of interpretation}

Compared with translation, interpretation activities are tightly connected with speaking. Domestically, the Chinese great translation theorist $\mathrm{Yan} \mathrm{Fu}$ once pointed out the translation standard as "faithfulness, expressiveness and elegance"; Fu Lei thought that translation is featured with "resemblance in spirit"; Lu Xun stressed "concerning both literally and liberally for comprehensiveness", and Qian Zhongshu concluded the feature of the translation as "perfectness".

Foreign demand for translation is the equivalence between target language and source language. However, all these theories and viewpoints are unsuitable for interpretation because interpretation focuses more on instantaneity, which is far from reaching the above criteria. Interpretation only pursues accuracy (the accurate absorption and comprehension of source language information), instantaneity (information recording and processing speed), fluency (dealing with information smoothly) and coherence (accurate processing and expression of the connotation, implied meaning and emotional color of source language information).

If the interpreting process is structuralized, interpreting activities are equivalent to oral English and translation. Therefore, the evaluation of interpretation is established on the basis of proficiency of oral English and effectiveness of translation, which is summarized as follows:
TABLE I. THE FEATURES AND PERFORMANCE EVALUATION OF INTERPRETATION

\begin{tabular}{|c|c|}
\hline Timeliness & $\begin{array}{c}\text { Translator's listening, short memories and } \\
\text { bilingual translation ability }\end{array}$ \\
\cline { 1 - 2 } Extemporaneousness & $\begin{array}{c}\text { In the face of unpredictable sudden subject, } \\
\text { the translator should solve problems } \\
\text { independently and flexibly }\end{array}$ \\
\cline { 1 - 2 } Unpredictability & $\begin{array}{c}\text { The translator should be provided with not } \\
\text { only bilingual professional knowledge but } \\
\text { also the basic knowledge of all walks of } \\
\text { life }\end{array}$ \\
\cline { 1 - 2 } Oriversity & $\begin{array}{c}\text { The translator must grasp the changes of } \\
\text { vocabulary, pronunciation, grammar and } \\
\text { semantics in oral English }\end{array}$ \\
Comprehensiveness & $\begin{array}{c}\text { The translator must strive to achieve } \\
\text { "integrated, comprehensive and } \\
\text { diversified”, keep all eyes and all ears and } \\
\text { accomplish the tasks with ease in } \\
\text { conversation translation }\end{array}$ \\
\hline
\end{tabular}

\section{Forms of interpretation}

\section{1) Alternating interpretation}

Interpretation is carried out alternately between two languages, which require the interpreter to transfer the meaning frequently among the parties involved.

\section{2) Simultaneous interpretation}

Simultaneous Interpretation is the process of interpreting the words of one language into another at the same time as the presenter is speaking. Interpreters (two or more per language) are stationed in a sound proof booth looking onto the conference area. The interpreters listen to a speaker through earphones, and simultaneously transmit the message into another language (target language) through a microphone to listeners in the room.

\section{3) Consecutive interpretation}

Consecutive Interpretation involves a two-step process during a meeting. First, the presenter speaks for a short period of time while the interpreter listens. Then, the interpreter renders the meaning into another language (target language). Although special equipment is not required, this method may require additional time for the meeting.

\section{Process of interpretation}

It is generally recognized that interpreting requires more than just knowledge of two languages. It is also well established among interpreter trainers and theoreticians that comprehension of the source language discourse goes beyond the simple recognition of words and linguistic structures. However, there have been few efforts to investigate scientifically the nature and extent of comprehension in interpretation before Daniel Gile' s Basic Concepts and Models for Interpreter and Translator Training. Daniel Gile describes the relationship between the knowledge of language, the extralinguistic knowledge and analysis in the following way:

$\mathrm{C}=\mathrm{KL}+\mathrm{ELK}+\mathrm{A}$

$\mathrm{C}$ stands for comprehension

KL stands for knowledge of the language

EKL stands for extra-linguistic knowledge

A stands for analysis 
"=”does not mean "equality" but refers to the result of the interaction between KL, ELK and A+ means addition by interaction, rather than arithmetic addition.

According to this, the specific process of interpretation in this paper can be summarized as follows:

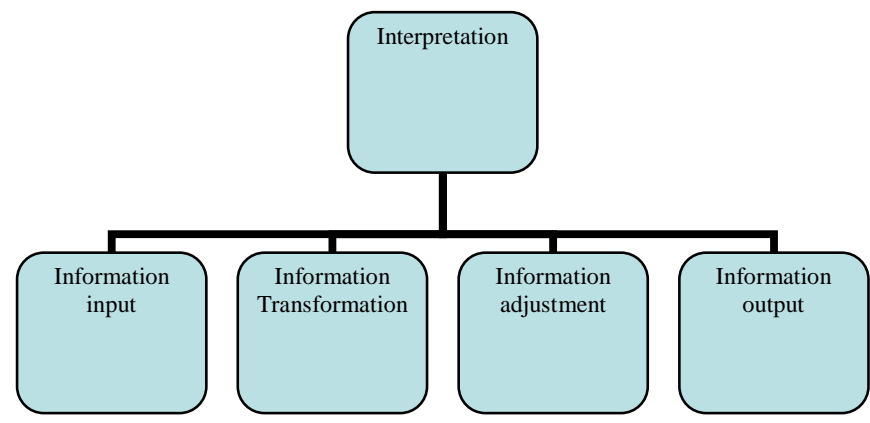

Fig. 1. Specific process of interpretation

\section{CORRELATION BETWEEN ORAL ENGLISH AND INTERPRETATION}

Interpretation is a process to transform source language to target language and convey the information to target language recipients. No matter from its connotation or process, there is an inseparable relationship between oral English and interpretation. Interpreter experiences three links during the process, input of original information (listening), processing of the input information, (translating) and output of translated information (speaking). In this process, oral language plays a role of information medium, that is to say, the demand for interpretation is based on oral language and cannot be separated from oral language[3].

\section{A. Similarities between oral English and interpretation}

An excellent interpreter must have at least two basic abilities. On the one hand, accurate and flexible application of the source language and target language; On the other hand, able to express information fluently in the source language and target language. The latter one determines the correlation between oral language and interpretation.

First, interpretation and oral language must be conducted with the aid of vocal organs because both activities are not written translation, but aim to convey information through exchange of words. As stated earlier, there is common ground between the features of oral language and interpretation, such as the pronunciation, intonation, speech patterns and discourse pause, which to different extent influence and determine the effectiveness of the communication. Interpreter, with pronunciation organs function: correct speech, appropriate intonation, proper way of speaking and appropriate discourse pause can transmit the output information of the source language to the target language recipients, supplemented by body language and facial expressions, so as to effectively promote the communication.

Secondly, in interpreting activities, the translators are unable to store the message effectively without the help of recording device or equipment because the memory of translator can be short and fragmental at the scene of the interpreting activities rather than long-term and complete, and it determines the differences between oral language and interpretation. However, it is just because of the difference that interpretation in relative to oral language is more operable. So, related researches on oral English and interpretation correspondingly lag behind that on translation. If both research and practice can be combined with each other, it will essentially promote the study on the correlation between oral English and interpretation[4].

Thirdly, oral language and interpretation have common in short-term effect because information in the two processes is conveyed through exchange of words, which cannot be stored completely in brain. Another similarity lays the rapidity of information transmission.

Finally, in the process of oral language expression and interpretation, information feedback is also quite rapid. Translators and recipients in the process of communication can determine whether the other side can receive and recognize the message effectively by capturing body language and facial expression. According to the reaction of the other side, they can detect and assess language expression so as to accordingly add the missing information, explain the fuzzy information in detail and even ask other people for help.

\section{B. Influence of oral language expression on interpretation}

Since there were some common aspects in oral English expression and interpretation, some typical characteristics of oral English will affect interpretation result to a certain extent. In general, the following characteristics of oral English will affect the performance of translator and interpretation results.

First, burdensome and laggard language expression and repetitive logical relationship will exert the greatest influence. In general there is inner logic in oral expression, but the internal system of thinking is not fixed, but transfer with the change of the topic and content of conversation. When the mind of the translator is influenced by the external environment or other element, it is easy for interpreter to digress from the subject or chatter without stop. Under normal circumstances, certain repetition can be called effective amplification in interpreting, but if the translator magnificently and miraculously gets free from the topic in an unconstrained style, the loss will outweigh the gain.

Second, translator in oral conversation will easily omit or ignore important information, and this kind of unconscious information omission is the second major influence on interpreting result. This will, of course, influence the correct information in the source language to a great extent, which results in the reduction in the efficiency of the whole conversation.

Third, the arbitrariness of the oral language also determines the mistranslation, misleading the listener's understanding of information. Whether it's translation error of pronunciation, vocabulary or sentence organization, it will make the whole conversation efficiency plummets. The mistranslation phenomenon can be generated by differences in education 
background, culture, custom and so on, and may also be derived from the different way of thinking[5].

Fourthly, the translator's own viewpoints, feelings and understanding will also affect interpretation. Whether the translator's own thinking is rational or his attitude one-sided, translator have no right to cause interference and change to the source language information and distort the speaker's point of view, which is also the restriction of oral expression to interpreting efficiency.

Since oral language has a major influence on interpreting and the two also have common grounds which cannot be ignored, determining there exists natural correlation between oral English and interpretation. Therefore, in college English interpreting teaching, teachers should instruct students to become conscious of the similarities between oral language and interpretation, on this basis, oral English teaching can be effectively carried out by integrating the characteristics of oral English into interpretation training, achieving the high efficiency of interpretation teaching.

Based on the research and analysis of this paper, the author puts forward the influence of the correlation between oral English expression and interpreting on the interpreting teaching in colleges and universities.

\section{INFLUENCE ON COLLEGE INTERPRETATION TEACHING}

The article "Chinese translation" clearly emphasized the differences between oral language and interpretation: Interpreting class is different from the oral English class, because oral English class is a process from input of language to the output of language, especially its interactivity, randomness and looseness involve mostly about the content of the daily work and life. Interpreting class is obviously more complicated than oral English class, which requires students to lay a solid foundation of basic skills in bilingual knowledge, at the same time, gradually get fluent bilingual competence and translation ability, involving the subject of current affairs and business negotiation.

In fact, in terms of college English teaching, the commonness between spoken language and interpreting could be used accordingly. As is stated earlier, interpreting's features of timeliness; diversity, extensiveness and comprehensiveness involve its requirements for translators in all aspects in interpreting activities: having flexible interaction ability, comprehensive professional and industry knowledge and ability of handling crisis of random strain, which is closely related to the requirement of oral English. In addition, occasions of oral English expression and interpretation happen to coincide to a certain extent. Their correlation exists in various aspects of social life, business negotiation, academic exchanges and international cooperation, which all require teachers and students to pay much attention to oral English expression in learning English. Only considering the correlation between oral English expression and interpretation can the maximum value of learning English be realized.
The author suggests that in college English teaching, the students can firstly enter interpreting from oral English expression. On the basis of improving their English interpretation skills, they can step into the interpretation. Secondly, English teachers can regularly organize English speech topics, scene dialogues, oral presentations and other activities to create space for students to perform themselves in oral expression and make qualitative evaluation of the performance.

In addition, in the process of English intensive reading and extensive reading teaching, warming up activities before class can be carried out appropriately. On the basis of understanding the main ideas of the text, students can roughly present the content and overview and retell the story through selforganization so as to improve the language expression skills. This part mainly is to cultivate the students' English thinking and consciousness, making them form independent language expression ability in the process of choosing words organizing language and screening information. Finally, interpretation can also be introduced into classroom consciously[6].

\section{CONCLUSION}

With the rising status of interpreting in English skills, interpreting course is becoming more and more popular and gets the favor of students in colleges and universities. Students, in the process of interpreting skills, are hard to avoid being restrained by oral English expression, therefore, English teachers must pay attention to the correlation between oral language and interpreting and the influence of oral English expression on effect of interpreting. Through the analysis and research in this paper, the characteristics of oral language to a great extent affect the implementation of the interpreting quality. The author believes that the translator must start from the oral language, understand its characteristics, find the commonalities and differences and explore its influence on interpretation so as to implement efficient interpretation. In college English teaching, teachers should also consider this and adjust the teaching methods so that students can really do it step by step in English learning.

\section{REFERENCES}

[1] Pao Gang, An Overview of Interpretation Theories, Tourism education press, 1998

[2] Chen Zhengrong, "Engineering and technical personnel in interpretation”, Chinese Science and technology translation,1998,11(3)

[3] Wang Xiaoyan. The characteristics of interpreting and interpreting teaching[J]. Chinese Translators Journal, 2003(6): 56-58

[4] Zhong Weihe. The knowledge structure of interpreter and interpreting curriculum[J]. Chinese Translators Journal, 2003, (4): 63-65

[5] Yang Baojun. Face training in college oral English[J]. Chinese Translators Journal, 2003, (3): 37-39

[6] Mei Deming. Advanced Interpretation Course [M ]. Shanghai: Shanghai foreign language education press, 2000, 6 